\title{
Abordaje de los conflictos estudiantiles en la gestión de las organizaciones educativas de primaria
}

\author{
Addressing student conflict in the management of Elementary School organizations
}

\author{
Lucrecia López Martínez' \\ Docente, Ministerio de Educación Pública \\ llopezmati@yahoo.es
}

Recibido 20 noviembre 2011 • Aceptado 11 diciembre 2012 • Corregido 13 de diciembre 2012

Resumen. En este artículo se analiza la gestión de los conflictos estudiantiles en las organizaciones educativas, específicamente en las escuelas Barrio Limoncito y La Colina, del circuito escolar 02, de la Dirección Regional de Educación de Limón. La metodología de la investigación es cuantitativa con un alcance descriptivo utiliza técnicas e instrumentos de recolección de información cualitativos y cuantitativos. el objetivo general del estudio es analizar el abordaje de los conflictos estudiantiles por parte de la gestión de estos centros educativos participantes y los objetivos específicos: determinar los diferentes conflictos estudiantiles que se presentan en las instituciones participantes, identificar las principales causas que generan los conflictos estudiantiles en las escuelas en mención, determinar las estrategias de gestión empleadas por el administrador de la educación para abordar conflictos estudiantiles y determinar los principales obstáculos que los conflictos estudiantiles, le generan a la gestión de los centros educativos Barrio Limoncito y La Colina.

Palabras claves. Gestión de la educación, administración de la Educación, Conflictos estudiantiles, educación.

Abstract. The author addresses the student conflict management in educational organizations, particularly in Barrio Limoncito and La Colina schools, from the school circuit 02, of the Regional Bureau of Education of Limon. Research is descriptive; using qualitative and quantitative research techniques. The overall objective of the study is to analyze the approach to student conflicts as part of the management of the schools participating and as specific objectives: to determine the different student conflicts that arise in the participating institutions, identify the main causes that generate student conflict in the schools mentioned, to determine the management strategies employed by the administrator of education to address student conflicts and identify the main obstacles that these conflicts generate to the management of Barrio Limoncito and La Colina schools.

Keywords. Education management, education administration, student conflicts, education.

\footnotetext{
Máster en Ciencias de la Educación con énfasis en Administración Educativa de la Universidad de Costa Rica (UCR). Máster en Administración Educativa de la Universidad Metropolitana Castro Carazo. Bachiller y Licenciada en Ciencias de la Educación con énfasis en I y II Ciclo de la Universidad Florencio del Castillo. Además posee un Técnico Superior en Administración del Currículo Educativo y Técnico Profesional en Pedagogía del Instituto Tecnológico de Innovaciones Productivas Sede del Atlántico. Actualmente se desempeña como docente y asistente de dirección en el Centro Educativo Barrio Limoncito, en la provincia de Limón, Costa Rica.
} 


\section{Introducción}

\section{Contextualización}

En el actual contexto mundial, son muchos los desafíos que enfrenta la sociedad, esto provoca una transformación en el desarrollo del individuo, precisamente, es en esta área que el sistema educativo requiere que los profesionales en administración de la educación, asuman en forma adecuada, la gestión de las organizaciones educativas, con el propósito de lograr la formación integral de las personas, de manera que éstas logren una eficiente y eficaz inserción social, económica y cultural que responda a las demandas de una sociedad en constante cambio; es una responsabilidad insoluble y un rol imprescindible de la administración de la educación para el desarrollo social y económico del país.

Los diversos conflictos sociales que acogen la sociedad mundial y en especial la sociedad costarricense, son de naturaleza multicausal que exige un análisis y abordaje interinstitucional y multidisciplinario. El contexto en el cual se encuentran inmersas las organizaciones educativas en la actualidad es complejo, esto debido a la variedad de situaciones conflictivas que se centran a diario dentro y fuera de las organizaciones educativas.

Los desafíos que generan los avances científicos, tecnológicos y sociales globales, forman parte de los retos y desafíos que enfrenta el sistema educativo nacional, en todas sus etapas y en cuanto a la formación de las nuevas generaciones de manera que éstas, respondan a las demandas de la sociedad.

Esencialmente en la capacidad de aprendizaje, las destrezas laborales y las competencias personales para enfrentar los problemas y retos de una sociedad compleja. La sociedad actual exige el comportamiento del ser humano a un conjunto de normativas, indispensables para operar en la compleja sociedad, tal y como lo expone Taberne (2009), al considerar que el orden normativo no siempre se ajusta a un individuo en forma particular, lo hace en el orden colectivo, sino que la complejidad en que vive la sociedad, es lo que genera la variedad de pensamiento en el individuo, genera un ser con facilidad de razonar y decidir, a su vez provoca que en ocasiones no se logre un consenso entre el individuo y lo establecido por la sociedad, creando diversos conflictos sociales.

Otro motivador de cambio en la sociedad es la democracia en los pueblos de cada ciudad, país, región, tal y como lo considera Jaramillo (2004) "más que un sistema político, la democracia es una forma de vida, es una actitud que todo el pueblo mantiene ante los valores, una vivencia, que solo con el tiempo se consolida" (p. 143). Esto afirma, que la democracia debe dar bienestar, oportunidad y ser justa con cada ser humano; por lo que los cambios hacia la globalización debe incluir la democracia social. 
Otra área que se debe incluir en estos cambios es el sector económico, al proyectar un desarrollo económico debe existir un desarrollo social, es decir se deben entrelazar uno con otro; al respecto, Jaramillo (2004) plantea que los gastos en salud y educación en países desarrollados como Suecia, Canadá, Finlandia, Holanda, Japón e incluso Costa Rica, entre los países en vías de desarrollo, han hecho ver que esto es una inversión social, llamada a proteger la salud y educar al capital humano, la mayor riqueza con que cuenta una nación.

Invertir en salud y educación trasciende a la convivencia social, es una de las maneras importantes en que la sociedad logra relaciones en cada área del desarrollo social. Ante esta perspectiva, las organizaciones educativas en general se desenvuelven en un entorno cambiante, competitivo y desafiante, de manera que se requiere que los individuos adquieran nuevas competencias que los integren de forma rápida y constante para que logren una adaptación al constante cambio. Así, las organizaciones deben ir sistematizando sus procesos de cambio, rediseñando sus modelos y estructuras, de tal forma que respondan y se adapten a los nuevos entornos y exigencias que la sociedad, en general y la sociedad del conocimiento y la información en particular, demandan.

Las instituciones educativas deben desarrollar actividades que fomenten las capacidades en la población estudiantil para enfrentar los períodos críticos y prepararlos ante los cambios que estas crisis exigen; ante todo, las organizaciones deben aprender a ser flexibles ante los nuevos retos, las nuevas variables y exigencias de la sociedad del conocimiento, Fernández (2001) anota lo siguiente, "por tanto las instituciones tienen que gestionar sus conocimientos para mantenerse vivas (...) su saber hacer es lo que les va a permitir innovar, y con la innovación perdurar" (p. 25). Este principio apodera al gestor y gestora de la educación como el eje primordial de mantener a su personal con las energías y el conocimiento vivos, puesto que esta actitud mantendrá vivo el interés por ser mejores cada día y brindar un servicio de calidad.

Ante esta realidad, a los profesionales en administración de la educación se le presentan distintos retos, por lo tanto, debe también, adaptarse a cambios constantes, que el nuevo modelo económico-social emergente exige. Esto significa, en el campo administrativo, un replanteamiento de sus modos y usos habituales de actuar, bajo la influencia del actual momento histórico, social, político y económico de tendencia globalizante, en un mundo que cada vez se hace más cercano, caracterizado por la globalización de la economía, lo que ha traído consigo el incremento de la pobreza, individualismo, desempleo, conflictos armados y otros, como lo indican Garbanzo y Orozco (2010) al referirse a los sistemas educativos dentro de la sociedad del conocimiento: "la sociedad del conocimiento, como se le denomina hoy, necesita sistemas educativos con capacidad para aprender y desarrollar nuevas competencias" (p. 18). De esta forma, los profesionales en administración de la educación deben crear ambientes innovadores, donde se involucre al personal docente y a la población estudiantil 
para interactuar en conjunto en busca de espacios, desarrollo de actividades o competencias entre sí, en beneficio de un ambiente sano y procurando evitar los conflictos estudiantiles.

Parte del desarrollo que se da en el área gerencial se debe a la implementación que ha gestionado la Organización de las Naciones Unidas para la Educación, la Ciencia y la Cultura (UNESCO), ante los estados que forman parte de esta organización, en busca de aprobar reformas importantes en los sistemas educativos, como la concentración, tal como refieren en su informe Delors, Mufti, Amagi, Carneiro, Chung, Geremek y Nanzhao (1996), "la Comisión destaca la conveniencia de una descentralización inteligente, que permita incrementar la responsabilidad y la capacidad de innovación de cada establecimiento escolar" (p.26). Está claro que esta reforma se podrá implementar en tanto exista compromiso político, económico y social por desarrollar una cultura de armonía continua.

En relación con la búsqueda del éxito en la implementación de una reforma educativa, Delors et al. (1996) agregan que:

tres agentes principales coadyuvan al éxito de las reformas educativas: en primer lugar, la comunidad local y, sobre todo, los padres, los directores de los establecimientos de enseñanza y los docentes; en segundo lugar, las autoridades públicas $\mathrm{y}$, por último, la comunidad internacional. La labor reformadora de la educación es responsabilidad de todos los que forman parte de la comunidad del centro escolar, dentro y fuera de este. (p. 24)

Así, la UNESCO, en el año 1996, como organismo internacional a través de la Comisión Internacional sobre la Educación para el Siglo XXI, en su informe, identifica la condición actual de la educación en todos sus ámbitos, apelando a la importancia de una mejor formación por parte de los docentes, la educación y la lucha contra las exclusiones, la educación para el desarrollo humano, al papel del político en la toma de decisiones que conlleva a la evaluación y el debate público, al tiempo que se habla de innovación, autonomía y armonía de los establecimientos educativos. La visión que proyecta la UNESCO, hacia la cooperación internacional, en cuanto a educar la aldea global está dirigida a una educación para la igualdad y el desarrollo social; busca la Organización, desarrollar una enseñanza de calidad, entre los sistemas educativos de los Estados que la conforman.

Es evidente entonces, que la comunidad realizará los esfuerzos necesarios para lograr que el proceso educativo responda a las necesidades reales de la misma, en lo social y económico. Reconociéndose a sí misma como impulsora del desarrollo productivo, en donde el mayor impulso proviene del compromiso social por el bienestar general y para ello, deberá conocer 
muy bien cada ámbito del centro educativo y sus necesidades o carencias. La sociedad actual enfrenta grandes retos en lo que respecta a los cambios acelerados, originados por los avances tecnológicos y por la sociedad del conocimiento que demandan, transformaciones de manera continua y eficaz en el sistema educativo vigente para asumir con responsabilidad una educación de calidad dirigida a las nuevas generaciones

Los elementos que caracterizan los sistemas escolares actuales fueron establecidos bajo el principio de la educación masificada y, entre sus principales características se pueden citar: la estructura jerárquica, el trabajo individual y el currículo estandarizado, lo que ha permitido el control de la población estudiantil. Aunque el modelo escolar que perdura hasta en la actualidad corresponde una escolarización masiva originada por la sociedad Industrial; sistema que fue necesario para dar respuesta al sistema económico emergente de la época. Aunque el modelo escolar actual puede ofrecer estabilidad y comodidad, como resultado de la rutina y la estandarización, en realidad es incompatible con la realidad global que se experimenta en la actualidad, que está expuesta a constantes cambios y demanda la actualización del conocimiento, así como la adquisición de las herramientas y competencias necesarias para enfrentar con éxito los retos que la sociedad presenta a las nuevas generaciones, presentando entonces diversos enfrentamientos entre los mismos, y posiblemente brote como un conflicto.

Es evidente entonces, que existe un problema fundamental, como lo señala Romero (2004), entre dos fuerzas poderosas, "(...) un mundo que cambia aceleradamente y una escuela que pretende permanecer idéntica a sí misma" (p. 20). Se evidencia así, que los cambios que se presentan en los sistemas escolares son resultado de los movimientos de origen extraescolar.

Con base en las consideraciones anteriores, se establece la importancia de instaurar procedimientos adecuados para crear ambientes armoniosos y un adecuado abordaje de los conflictos estudiantiles que se presenten dentro de las instituciones educativas así, como sus procesos dentro de las organizaciones, en busca que se identifiquen aquellas necesidades que requieren ser atendidas para propiciar el cambio y la mejora. En la consecución de esta acción, las profesionales gestores de la educación tienen un rol predominante. Es a través de la gestión de la educación que cada organización pedagógica puede buscar, crear o innovar la manera que logre desarrollar entre sus miembros la construcción de estrategias necesarias para optimizar el servicio de educación que ofrece a la comunidad estudiantil, así mismo, las capacidades que la habiliten para enfrentar los retos laborales que la sociedad impone. Las poblaciones juveniles y de infantes son quienes conforman un gran porcentaje de la ciudadanía civil, consideradas poblaciones vulnerables. 


\section{Justificación e importancia del problema de investigación}

Las organizaciones educativas evidencian esta realidad, por lo que, es frecuente, últimamente, escuchar información relacionada con diferentes problemas, dentro de los cuales se hace referencia a los conflictos en los centros escolares, generalmente descargan en actos de violencia o agresiones, que quizás pudieron haberse evitado, y que generan un impacto negativo en el proceso educativo que se ejecuta en las organizaciones educativas. Este entorno, en el sistema educativo costarricense no está exento de los conflictos estudiantiles en sus centros educativos, el incidente en el que dos escolares recibieron heridas de armas de fuego mientras se hallaban bajo la "protección" de una escuela, provocó naturales reacciones de asombro e indignación. Ante esta situación, Durán (2007) menciona que ningún centro educativo está exento, siendo que existe la posibilidad de que la población estudiantil presente dificultades emocionales que terminan dañando a otros compañeros y compañeras. Sin embargo, se deben seguir buscando acciones que ayuden a dar un mejor tratamiento a estas situaciones, por lo que la administración de la educación es fundamental en este proceso.

Esta situación se refleja en las diferentes conductas de la juventud, generalizando conflictos que, de no ser abordados adecuadamente, podrían desencadenar en violencia. Los estudios sobre conflictos estudiantiles y las respectivas propuestas para su atención, en su mayoría se circunscriben a hechos concretos al interno de las instituciones educativas y descontextualizadas del acontecer social y político de la sociedad, como por lo general se ha dado. En consecuencia, el propósito de la formación integral, en un marco cognitivo, socioafectivo y en una sociedad educadora, se ve significativamente afectado en su desarrollo.

Para disminuir los conflictos estudiantiles, así como los problemas de violencia estudiantil, dentro y fuera de las aulas, es importante determinar los tipos de conflictos prevalecientes en la población estudiantil, los cuales en su mayoría son de carácter interpersonal e inter-grupal de relación y comunicación, respectivamente. Estos conflictos se relacionan, a su vez, con los problemas económicos y familiares fundamentalmente.

Es así, que desde la administración de la educación se asume relevancia el generar espacios desde la gestión, para promover la sana convivencia estudiantil, tomando en cuenta que, en su mayoría, este tipo de problemas tiene un origen externo a la institución. Sin embargo, dentro de la institución también hay generadores de conflictos estudiantiles que quedan manifiestos en las relaciones entre estudiantes, como por ejemplo, aquellos asociados a la etnia, tolerancia en general, e inclusive con la relación que se establecen entre el mismo personal docente. De esta forma, es posible liderar un proyecto de gestión que promueva una cultura de tolerancia, con el fin de prevenir o minimizar los diferentes conflictos estudiantiles que se presentan en las instituciones educativas (Chacón, 2011). 
En la actualidad, la administración de la educación se presenta como un área de conocimiento humano con complejidades y desafíos. Las organizaciones son diferentes y es por ello, que quien las administra debe tener las capacidades y habilidades necesarias para desempeñarse efectivamente, en los niveles de la administración.

El análisis de los conflictos ha tomado en los últimos tiempos mayor apogeo en la investigación educativa, debido a su incremento, considerándose que debe ser materia de interés para los profesionales que administran las organizaciones educativas. A escala mundial, diversas instituciones se han preocupado por incentivar la paz y eliminar el conflicto entre los seres humanos, sobre todo en el contexto educativo, esto ha sido abordado por investigadores a nivel internacional. A pesar de que diferentes disciplinas sociales y educativas han estudiado la temática, estos centros educativos representan a una población vulnerable desde el punto de vista estudiantil. De igual forma, es indispensable analizar el papel preponderante de los profesionales en administración de la educación en el abordaje de los conflictos estudiantiles, con el propósito de que no interfieran en el logro de los fines y objetivos de la educación costarricense.

En la actualidad la sociedad enfrenta una serie de desafíos que buscan soluciones precisas para mejorar, de las cuales destaca la asertiva resolución y manejo de los conflictos. En el área educativa, esta responsabilidad se delega a los profesionales en administración de la educación.

De esta forma, se generan diferencias sociales alternado la sana convivencia entre el sujeto con el contexto en el que se desarrolla en la sociedad, lo que hace necesario un abordaje certero en la prevención y resolución de conflictos para lograr un incremento social armonioso. La sociedad de hoy, debe aprender a relacionarse con la complejidad de las relaciones sociales de las persona; cada ser humano debe interaccionar desde la infancia con el primer grupo, la familia y así sucesivamente, pasar por diferentes etapas a lo largo de su desarrollo, con el fin de avanzar con la sociedad, en busca de una adecuada convivencia entre el ser humano y su contexto. Este proceso integrador lo que busca es que los individuos mantengan su propia historia de vida, en los marcos de respeto colectivo; actuando con sus propios principios, logrando su socialización. Es en este momento, que se produce el comportamiento social entre las personas.

La familia es el primer agente socializador, ha enfrentado serios cambios, según la necesidad y condiciones del momento de la historia en que se enfrenta. En la actualidad las familias y la sociedad deben avanzar según la necesidad de un mundo globalizado y en busca de información constante, por lo que incita a un cambio importante en la forma de convivencia y provoca retos en la interacción social. 
Es por esta razón, que se necesita analizar detenidamente el papel que realiza la familia en la sociedad y, a su vez, en la educación, lo que implica distintas disfunciones, como lo expone García et al. (2002) al referirse a estas disfuncionalidades como aquellas diferencias que llevan a reflexionar y a buscar el cambio de manera relevante para las familias, para que los individuos logren integrarse respetando las reglas y normas de la misma y, de esta manera, las organizaciones educativas tendrían mejores condiciones de interrelación con su población estudiantil. Un ejemplo de una buena formación en el núcleo familiar que construye un ser humano ejemplar ante la sociedad es Martín Luther King, quien se caracterizó por abogar por una sociedad más justa, donde todos los hombres sean tratados por igual, donde no hayan diferencias; estas palabras permiten captar los valores éticos, morales y espirituales que se deseara para cualquier persona dentro de la sociedad y, en especial, es un llamado a implementar esta filosofía en las organizaciones educativas, donde la gestión tiene un papel relevante.

Aunado a la familia, los centros educativos conforman la principal instancia socializadora, cuya finalidad es continuar con la formación que se inicia en el hogar; sin olvidar la formación académica, se debe incluir la parte afectiva y moral de cada ser humano. Al respecto, los gestores y gestoras de instituciones educativas, se enfrentan a este reto, en aras de lograr los fines de la educación para formar ciudadanos amantes a su patria, logrando una convivencia social sana.

En la institución educativa se plantean estrategias que le ayudan a las personas a formar y desarrollar sus valores, para ampliar sus capacidades y lograr que sean mejores ciudadanos. En este sentido, la familia también juega un papel importante en la parte formativa del individuo. se deben crear tácticas educativas y administrativas que incluyan a la familia y a la escuela; es aquí, donde los profesionales en administración de la educación deben establecer esta relación, escuela-familia y comunidad, debido a que la sociedad es cambiante, por lo cual, incide en los cambios de rol en el hogar, para fomentar que cada ser humano adquiera conocimientos accesibles y actuales, relacionados con el desarrollo de la sociedad y que, como ser humano, libre y conocedor de las normas de convivencia, entienda que puede pensar diferente y comprender cada uno de los cambios a los que se expone la sociedad, como en los diversos medios de comunicación y tecnológicos.

La educación es uno de los ejes de interés de los políticos, principalmente en su período de campaña, ya que siempre en sus planes se enfocan siempre en busca del mejoramiento de la calidad de la educación. No obstante, cuando están colocados en el poder, no todo sale como lo planificado, ya que el presupuesto no se adapta, surgen diferentes cruces de intereses, lo cual posiciona al profesional en administración de la educación en una difícil posición. Con todo lo anterior, se dificulta poder obtener los logros deseados desde la educación del país. Continuando en este ámbito, se debe prestar atención al desarrollo de la población estudiantil en cada área, ya que es la razón de ser del sistema educativo. Por lo cual, el personal 
directivo, dentro de su papel como gestor y promotor de una educación de calidad y equidad, debe propiciar en su gestión espacios de trabajo en equipo, comunicación, liderazgo y de intervención de los conflictos.

La población discente es el componente principal en la educación, ya que es con base en ellos que se estudian, varían y buscan estrategias de aprendizaje, así como el proceso de adaptación a la convivencia con sus iguales. Por tales motivos, se ha investigado con fuerte énfasis el cómo piensan y razonan para lograr sus propias decisiones, según sus propios intereses. Esta posición concuerda con Gairín y Darder (2002) quienes expresan que es por esta razón que los profesionales en administración de la educación deben velar por ambientes armoniosos para que el proceso enseñanza-aprendizaje se desarrolle en óptimas condiciones y potenciar las capacidades de los individuos.

Ante esta realidad, la administración de la educación tiene un rol primordial en la toma de decisiones, por lo que de éste dependerá la calidad y la integración del alumnado a la sociedad; por medio de estructurar, organizar y coordinar estrategias para alcanzar los fines y objetivos de la educación. Asociado a esto, la población estudiantil se relaciona de diferentes formas dentro de la organización educativa, unos se adaptan con facilidad y aceptando lo que se le desea transmitir, otros aceptan el área académica con respeto, aunque no precisamente las reglas de la organización; también, están los que no lo aceptan, presentando gran resistencia, lo que causa que dentro del centro educativo se presentarán conflictos en forma constante. Por lo cual, se debe innovar en las acciones que buscan el mejoramiento al tratar situaciones de conflicto dentro de la organización.

La educación costarricense es orgullo y riqueza del país, es mediante ella que se ha forjado la idiosincrasia y su espíritu civilista. Es a través de la educación y de estos principios que el país ha surgido y desarrollado en el ámbito humano y económico que enaltece a la patria. Con este enfoque la administración de la educación debe fomentar la cultura de paz y valores, para la prevención de conflictos estudiantiles.

El enfoque de mejoramiento de la calidad de la educación en el curso lectivo, ha generado cambios como la duración de la población estudiantil en las aulas, así como emplear adecuadamente el tiempo, dentro y fuera de ellas; siempre para lograr la convivencia dentro de las instituciones. Es decir, que los y las profesionales en administración de la educación obtengan los resultados dentro del sistema educativo que garanticen la sostenibilidad de las relaciones sociales en el contexto actual (nacional) y un contexto a futuro (internacional); siempre velando por que los individuos obtengan un excelente desarrollo y ambiente; en el caso de que se pueda realizar un abordaje adecuado y preventivo para no alterar los fines de la educación. 
La cotidianidad de la administración de un centro educativo puede verse afectada por diferentes conflictos, no menos importantes los estudiantiles, que se suman a los complejos problemas de convivencia y subsistencia, una considerable carga emocional de difícil manejo.

En general, el retraso en el acceso a la responsabilidades individuales es consecuencia de una particular situación socioeconómica, a la que puede considerarse por lo tanto, un sistema general. Aunado a esto, se puede mencionar que la familia tiene mucha influencia en estas actitudes de conflictos que causan sus hijos e hijas en las instituciones, ya que en ocasiones los padres y madres de familia no aceptan que sus progenitores cometan ciertas conductas generadoras de conflictos, como lo expone Piaget citado por Smith (1996), el cual nos manifiesta que los conflictos estudiantiles son generados por distintas razones sociales, desde las organizaciones educativas y en especial, desde la administración de la educación interesa trabajar el tema en lo institucional, que es el campo de acción donde la administración de la educación puede incidir.

Una mirada a esta realidad obliga al replanteo de la formación de quienes tienen la responsabilidad de enseñar y retener dentro del sistema educativo a la población estudiantil que vive situaciones de conflictos dentro de la institución educativa. De lo anterior, se puede deducir que los conflictos estudiantiles, en la mayoría de los casos, no son claros, sino que se encuentran dentro del currículo oculto. Estas conductas se presentan con mayor frecuencia en los niños y las niñas de segundo ciclo y muchos de los y las estudiantes tienen actitudes de incumplimiento con tareas, trabajos, materiales, entre otros, y los padres y madres o encargados de estos niños y niñas no quieren ver la realidad de lo que se les dice; es el profesional en administración de la educación quien posee dentro de sus obligaciones, intervenir para evitar el crecimiento de los conflictos en su institución y alcanzar la colaboración de los padres y madres de familia con el estudiantado.

La educación es un deber y derecho de todos los individuos, por lo que se exige que se les guíe en el desarrollo personal, moral e intelectual. Y no se puede, ni se debe pretender que el alumnado se adapte al sistema escolar únicamente y hacer a un lado a aquel estudiante que no sabe cómo comportarse dentro de la sociedad educativa, si no en su lugar, buscar cómo integrar a estos individuos al área social. Por lo cual, el profesional en administración de la educación debe crear estrategias que prevengan futuros conflictos, que motiven a superarse y que toda la comunidad educativa sea conocedora de estas estrategias, así se vela por no infringir ese orden social.

El personal directivo debe estar atento y con responsabilidad social ante los conflictos estudiantiles en el plano institucional, ya que estos son algunos de los obstáculos para lograr los fines y objetivos de la educación costarricense. Se deben generar estrategias desde la gestión de la educación que den la oportunidad de atender, oportunamente y de manera 
eficaz, los posibles conflictos estudiantiles en las organizaciones educativas; ejemplo de esto es el reglamento interno de la institución. Los conflictos estudiantiles existen, deben ser manejados para evitar que pasen esa línea de respeto a la convivencia social y la vida.

La provincia de Limón se caracteriza por altos niveles de problemas sociales como alcoholismo, corrupción, tráfico de drogas, consumo de estupefacientes, conflictos sociales y altos niveles de violencia. En consecuencia los centros educativos en esta zona, presentan un mayor incremento de conflictos estudiantiles, razón por la cual los profesionales en administración de la educación, enfrentan en su gestión problemas asociados con estos conflictos, limitándoles el cumplimiento de sus objetivos del proyecto institucional.

Por todo lo anterior, surge el interés de abordar desde la administración de la educación, el tema de los conflictos estudiantiles en las organizaciones educativas, con el fin de ofrecer recomendaciones para la toma de decisiones en la gestión de este campo. La educación es el medio para lograr un cambio en las personas. Mediante ella, se puede lograr que los niños y niñas que protagonizan conflictos en sus aulas puedan lograr un cambio. En la actualidad, se ven constantemente las noticias donde narran los hechos lamentables de sucesos con menores de edad, quienes son protagonistas de serios conflictos en sus centros de estudio; tanto entre ellos mismos como con el personal docente. En vista de esto, Koontz y Weihrich (1990) sugieren que es tiempo de que los profesionales en el campo de la administración de la educación se tracen como objetivo tomar autoridad para mejorar la gestión de los conflictos en las instituciones educativas, fomentando la comunicación de los y las estudiantes, el personal docente y las familias buscan evitar los conflictos que causan dolor y la pérdida de los derechos del alumnado que sufre en los centros educativos.

Estos y otros problemas harán que la educación en el país enfrente una crisis que requiere el aporte de todos los actores sociales en la búsqueda de soluciones a la misma; que hagan real el acceso al derecho a la educación de los niños, niñas y adolescentes. Esta situación preocupa a los directores y directoras de las instituciones educativas sobre la falta de atención al problema de conflictos internos en los centros educativos, lo que podría contribuir con la formación de futuros delincuentes en lugar de profesionales. Se convierte en un reto para las autoridades comenzar un proceso de reestructuración de estas instituciones, no solo por sus áreas de trabajo, sino por su complejidad, sino también por su cultura organizacional. Las agresiones que sufren escolares quizás nunca se investiguen, pues mucho del personal docente no denuncian los casos que se presentan en los centros educativos. Si bien, en la escuela siempre se han presentado diversas situaciones de conflicto, los cambios sociales y culturales en la actualidad han hecho más sensible el conflicto a su interior.

Los conflictos escolares son un problema en las aulas del país, a pesar de los esfuerzos por parte del gobierno, el Ministerio de Educación Pública (MEP) desarrolla programas y proyectos 
para prevenir la violencia, el conflicto y fomentar la permanencia de la población estudiantil y los profesionales en el campo de la administración de la educación, con ayuda de las campañas y programas implementados en los centros educativos en los últimos años. Es así, que en este contexto, y con el propósito de abordar la gestión de los conflictos estudiantiles en los centros educativos, se han planteado los siguientes objetivos:

\section{Objetivo General}

Analizar el abordaje de los conflictos estudiantiles por parte de la gestión de la Escuela Barrio Limoncito y La Colina, Circuito Escolar 02 de la Dirección Regional de Limón.

\section{Objetivos específicos}

- Determinar los diferentes conflictos estudiantiles que se presentan en las instituciones Barrio Limoncito y La Colina.

- Identificar las principales causas que generan los conflictos estudiantiles en las escuelas Barrio Limoncito y La Colina.

- Determinar las estrategias de gestión empleadas por el administrador de la educación para abordar conflictos estudiantiles en los centros educativos Barrio Limoncito y La Colina.

- Determinar los principales obstáculos que los conflictos estudiantiles, le generan a la gestión de los centros educativos Barrio Limoncito y La Colina.

Al desarrollar estos objetivos se busca aportar insumos para la creación de estrategias de gestión para el abordaje de los conflictos estudiantiles en los centros educativos barrio Limoncito y La Colina, con el propósito de responder a interrogantes como: ¿cuáles son los diferentes conflictos estudiantiles?, ¿cuáles son las principales causas que generan los conflictos estudiantiles en las escuelas?, ¿qué estrategias de gestión emplea el administrador de la educación para abordar conflictos estudiantiles en los centros educativos?, ¿cuáles son los principales obstáculos que los conflictos estudiantiles, le generan a la gestión de los centros?

Para ello, se eligieron dos escuelas de la provincia de Limón, Costa Rica, porque sus comunidades se ven afectadas por diversos problemas, como consecuencia de los riegos en la propiedad, enfocados en especial la comunidad de Barrio Limoncito y La Colina, las cuales se 
ven afectadas en forma constante, por los conflictos estudiantiles, debido principalmente a las características socioeconómicas de la zona. Esta coyuntura da fundamento para la selección de estas instituciones educativas. Se espera que la población estudiantil pueda optar por mejores condiciones de convivencia, que no afecte su proceso de enseñanza-aprendizaje por estar solucionando los conflictos escolares, lo que provoca importantes limitaciones para alcanzar los objetivos educativos programados para lograr una educación de calidad. Los profesionales en administración de la educación, deben cumplir con su responsabilidad de saber resolver los conflictos para garantizar que el personal docente no se vea afectado en el desarrollo de los objetivos programados y así, garantizar que se concreten los fines de la educación costarricense.

Importante mencionar, que la escuela Barro Limoncito posee una amplia trayectoria académica que inició en el año 1976 y la escuela La Colina, fue fundada en 1984, ambas se encuentran en una zona urbano-marginal de la provincia de Limón, en Costa Rica. La escuela Limoncito es clasificada como dirección cinco, por contar con una matrícula superior a 850 estudiantes y entre personal docente y administrativo, poseer 64 funcionarios y funcionarias. La escuela La Colina considerada como una dirección cuatro, tiene una población de 500 discentes aproximadamente y consta de un personal docente y administrativo de 45 personas. Ambas instituciones son escuela líder, por pertenecer al proyecto de apoyo al Sistema Nacional de Mejoramiento de la Calidad, impulsado y ejecutado por el Ministerio de Educación Pública, con el asesoramiento técnico de la UNESCO y el apoyo financiero del Reino de los Países Bajos, Holanda; además, es calificada como escuela de Atención Prioritaria 2 , que es el programa para el Mejoramiento de la Calidad de la Educación y Vida en las comunidades Urbanas de Atención Prioritaria (PROMECUM) en donde se asume que si no hay educación, no hay desarrollo. Con éste, se pretende que las comunidades con menor índice de desarrollo social se desarrollen, bajo el mejoramiento de la calidad y las oportunidades de educación para los niños y las niñas. Ello permitirá mejorar el proceso integral y consecuentemente la condición económica u social de la colectividad educativa, en el mediano y largo plazo (Plan Institucional, Escuela Barrio Limoncito y Escuela La Colina, 2011).

\section{Marco teórico}

\section{Teoría de la educación y política educativa}

La base de las sociedades, desde los inicios de la humanidad, ha sido la educación, por lo cual se ha transformado en un factor del desarrollo en las naciones, las cuales, a través de la metodología y planificación adecuada, logran alcanzar los resultados esperados por los pueblos. A través de los años, las sociedades han dado más importancia a la cantidad y calidad de la educación que reciben las personas, logrando un mejoramiento continuo de los planeamientos 
y estrategias utilizados en la enseñanza. Cabe mencionar que esto, a su vez, conduce a que en la actualidad los métodos de evaluación sean más elevados y rigurosos, lo que genera mejores profesionales en las diferentes áreas donde la población estudiantil se capacita.

Esto tiene sus fundamentos en las enseñanzas que reciben los primeros maestros y maestras, los padres y madres de familia, quienes desde el momento del nacimiento dan inicio a la tarea de dar a los niños y niñas todas las herramientas básicas necesarias para desenvolverse dentro de la sociedad. A través del estudio y análisis del pensamiento humano, muchos pensadores coinciden en que la capacidad de obtener conocimiento por medio de la educación es muy amplia; entre ellos se pueden citar a Piaget, Sócrates, Aristóteles, Rousseau, Freud, entre otros.

Se puede destacar que la sociedad moderna otorga particular importancia al concepto de educación permanente o continua que establece que el proceso educativo, no se limita a la niñez y juventud, sino que el ser humano debe adquirir conocimientos a lo largo de toda su vida. Es por esto, que el Ministerio de Educación Pública (1994), en su programa La Política Educativa hacia el Siglo XXI, que aún prevalece en los programas educativos, manifiesta que la educación costarricense se ve sustentada por tres fuentes filosóficas; las mismas están dentro de la ley fundamental de la educación y la dignidad del ser humano,

En donde se espera desde la fuente humanista promover la libertad de búsqueda de los valores que cada individuo debe poseer; la constructivista plantea que en conjunto (educador o educadora y estudiante), se logre la construcción del conocimiento en la enseñanza-aprendizaje, es decir que ambos individuos participen en la educación para lograr que se de calidad y excelencia. La visión humanista busca que la población estudiantil esté inmersa dentro del proceso de enseñanza-aprendizaje, de una manera sistemática.

Se afirma así que "la existencia de múltiples representaciones sobre educación, que en nuestra reflexión constituye un punto de partida inexcusable, se convierte para otros en un indicio de la imposibilidad de hacer Teoría de la Educación" (O'Connor (1971), citado por García y García, 1996, p. 273). Con lo anterior, se evidencia que la teoría de la educación es dinámica y flexible.

El progreso de esta teoría se encuentra modelado por el conocimiento del ser humano, razón por la cual, el personal docente debe realizar las diferentes estrategias metodológicas según su contexto curricular y social, fabricando sus propios conocimientos para actuar según las exigencias del momento. Argudín (2006) concuerda al afirmar que el ser humano vive una continua transformación durante el proceso de aprendizaje, lo que demuestra que el aprendizaje y la educación no son lo mismo, sino que la educación es lo que le queda al ser humano después de olvidar lo aprendido, es decir, no precisamente el que posea el titulo mayor sea el que tenga más educación para desarrollar un cargo, sino el que allá obtenido mejor aprendizaje en su desarrollo. 
Junto al concepto de educación existe una estrecha relación con el profesional que ejerce el papel de educador o educadora, quienes son personas ejemplo para copiar una conducta, forma de pensar o actuar, por dicha razón cualquier persona del contexto puede ser un reflejo docente. Así, Sancho (1929), citado por Rodríguez (2001) considera que el personal docente debe tener gusto por lo que realiza, lo que deja claro que la labor del educador o educadora, debe tener como propiedad la entrega total a su estudiantado y ser ejemplo de la vivencia de los valores que representa, así como la función de transmitir conocimientos académicos.

Tomando en cuenta el aporte de los autores mencionados, se considera de importancia realizar un cambio en la labor de las organizaciones educativas actuales, ya que la falta de la formación de los valores han transformado el fin de la educación y ha dejado ver la formación social para crear un ambiente en armonía, mientras que la administración busca sobrellevar la responsabilidad de atender oportunamente los conflictos que surgen en las organizaciones educativas.

\section{Administración}

La administración hace referencia a un individuo que ejecuta una función bajo el mando de otro, es decir quien presta un servicio a otra persona, La administración ha tenido un desarrollo teórico principalmente a partir de la mitad del siglo XX, con los primeros gestores de la administración, Fayol y Taylor. En ese sentido, Chiavenato (2006) puntualiza en que la conceptualización de este término, incluye elementos fundamentales para el cumplimiento de los objetivos organizacionales, tales como la planeación, organización, entre otros, que permiten se lleve a cabo. Se puede destacar en la administración de las organizaciones, las acciones de planificación, dirección y control de los procesos que llevan a la calidad en el producto o los servicios que ofrece, a través de una óptima utilización de los recursos que la sociedad pone a su disposición, mediante la acción planificada de los objetivos organizacionales. Lo anterior, vuelve indispensable el papel del profesional en administración.

El crecimiento acelerado y desorganizado de las empresas exigió un enfoque científico, con lo que surgen las condiciones de planeamiento a largo plazo y se reduce la improvisación para lograr adquirir el éxito y las ganancias por medio de la planificación, por lo cual los procesos de desarrollo se deben realizar por medio de una plan elaborado partiendo de un diagnostico y así, alcanzar la victoria. Por todo este proceso, profesionales en la ingeniería de la administración científica se basaron en los principios de la administración científica de Taylor, los cuales dan sustento a los postulados teóricos (Chiavenato, 2006).

Teniendo en cuenta estos cuatro principios, es probable obtener una administración científica eficaz, que permite estar al frente de cualquier empresa y salir adelante. En el primer 
principio se hace referencia a que se debe conocer y diagnosticar el campo en que se está incluyendo; posterior a este, se pasa al segundo, el cual es preparar el campo tanto en la parte humana como la material, para pasar al tercer principio, el buen control de todo y por último, la ejecución con la seguridad de lo que se requiere y desea.

De esta manera, Fayol, citado por Chiavenato (2006), desarrolla la teoría clásica, lo cual enfatiza la búsqueda de la eficiencia empresarial por medio de la promulgación y aplicación de catorce principios generales de la administración. Todos estos principios y conceptos correspondientes a la teoría de la administración en general, son aplicables en el área de la educación, puesto que es necesario alcanzar una educación de calidad.

\section{Administración de la educación}

El ser humano es consciente de que debe ser ordenado y poseer una coordinación racional de todos los recursos que forman parte del grupo social al cual está vinculado, esta etapa corresponde al proceso administrativo conocido como organización. Es gracias a la organización que se puede plantear qué medidas o estrategias utilizar para lograr los objetivos planteados.

Los profesionales en el campo de la administración de la educación deben ser facilitadores del cambio, agentes de transformación institucional encargados de colaborar y brindar las herramientas necesarias al personal docente $y$, en general, a toda la comunidad educativa, de tal forma que se sientan en la capacidad de enfrentar los diferentes retos que se le presentan en el nivel social, cultural y humano.

De esta forma, el abordaje eficiente de los conflictos por parte del profesional en administración de la educación, implica por su parte mucha dedicación y compromiso personal, sobre todo porque iniciar un programa para el mejoramiento de la comunicación, la motivación, la confianza y la generación de proyectos institucionales que contribuyan al crecimiento humano y técnico del personal y al mejoramiento de la calidad educativa institucional, es una tarea ardua para la buena marcha de la institución (Chacón, 2011). De ahí, que deben generar proyectos que contribuyan al fomento de una convivencia sana entre los miembros de la comunidad educativa y sus diferentes vinculaciones con el contexto más cercano.

Uno de los objetivos fundamentales de la administración de la educación es ofrecer los mejores servicios educativos por medio de una adecuada utilización de los recursos que la misma sociedad pone a su disposición; lo anterior, a través de acciones que se planifican conforme a los objetivos organizacionales, los cuales son orientados en su desarrollo por el profesional en administración de la educación en los centros educativos, para un mejoramiento 
del desempeño del recurso humano y material en ese sentido (Chacón, Elizondo, Fernández, Triana y Umaña, 2009). De esta forma, la unción de la administración de la educación se considera compleja y variada, ante la diversidad de tareas que desarrolla para beneficio de las organizaciones educativas. Algunos teóricos se refieren a las características más importantes que describen el perfil del profesional en administración de la educación, las cuales se desarrollan seguidamente.

Todo profesional en administración de la educación, para desempeñar efectivamente su función conductora dentro de la institución, debe tener un temperamento equilibrado, tolerancia a la crítica, seguridad en sí mismo y capacidad de decisión, una continua autoevaluación de su quehacer mediante una actitud reflexiva de actuación con las normas establecidas, facilidad de comunicación, liderazgo y agilidad en la conducción de grupos (Chacón et al., 2009). Como complemento, a lo largo de la formación profesional y de la experiencia laboral en la administración de la educación, se deben desarrollar capacidades o habilidades para enfrentar con éxito las diversas situaciones que se le presentan.

La administración de la educación, por tanto, tiene un papel directivo en las organizaciones educativas, lo que requiere del desempeño de un buen liderazgo que procure la funcionalidad y calidad de los procesos que ahí se gestan, los cuales tienen su razón de ser en el aspecto pedagógico (Chacón et al., 2009). Sin embargo, las funciones son diversas y las habilidades también deben serlo, para responder con éxito a las demandas y retos que impone la sociedad actual.

Las definiciones aportadas están claramente enmarcadas aún en un enfoque clásico de la administración de la educación en donde los principios de la administración general, son evidentes en cuanto al control específicamente. Se hace necesario plantear un nuevo paradigma de administración de la educación, flexible, que interprete y atienda con responsabilidad, junto con los otros actores sociales, las demandas la sociedad actual, la cual se caracteriza por los avances constantes en la tecnología y la globalización, en donde el sistema político y económico requiere de la formación de un nuevo ciudadano, con capacidades que le permitan enfrentar ese sistema con éxito.

La administración de la educación proporciona al gestor o gestora un instrumento que le ayude a estudiar la organización y la estructura de las instituciones que permitirá orientar en las funciones de planificación, organización, coordinación, dirección y control, en el programa a seguir. La administración de la educación tiene como objetivo el estudio del gobierno, en sus distintos grados académicos de primaria, secundaria, tercer ciclo y formal, lo que exige a los administrativos una adecuada organización para que se cumpla con todas y cada una de las características propias de cada nivel de formación de las y los individuos. 
Además se podría garantizar que un propósito básico de la educación es favorecer el desarrollo de la población estudiantil, de forma que vivan plenamente cada una de estas etapas de formación. El profesional en administración de la educación debe ejercer sus funciones de supervisión, planificación y gestión, para que los elementos del currículo se nutran de las disciplinas de fortalecimiento como la psicología, la filosofía, la sociología y algunas otras; sin perder de vista, la responsabilidad de que debe estar alerta para atender estratégicamente, los conflictos que brotan dentro del centro educativo.

\section{Gestión de la educación}

El término gestión proviene del latín y hace referencia a la acción y al efecto de gestionar o de administrar. Es realizar diligencias que conducen al logro de un objetivo en específico. La gestión directiva en las organizaciones educativas se fundamenta en el principio administrativo de hacer las cosas a través de la personas. Al respecto, Chiavenato (2000) afirma que la eficacia del trabajo en equipo para el logro de objetivos comunes, depende de la capacidad de las personas que se hacen cargo de la función administrativa. Desde la visión de la administración, la gestión de la educación tiene como principal objetivo, trabajar con las personas para lograr metas comunes que beneficien y ayuden al mejoramiento y calidad de la educación.

El rol de la persona que ejerce la dirección en una escuela con necesidad de cambio, en el manejo de los conflictos, necesita una transformación educativa, pensando este proceso como una necesidad de reflexión, análisis y cuestionamientos de sus propuestas, que orientan y reorientan la marcha institucional, con objeto de acomodarse a las necesidades de las demandas del alumnado, y como también de tomar una perspectiva crítica para poder modificar en función del desarrollo positivo de la sociedad que la sostiene (Castro, 2012; Vasconez, 2012). Sin perder de vista los fines de la educación en formar ciudadanos amantes y respetuosos a la patria. Lo que implica cambios tales que se modifiquen radicalmente las configuraciones institucionales, como lo mencionan Garbanzo y Orozco (2010), en donde destacan la importancia que se vive en un país democrático participativo, donde se destaca la importancia de las bases de las instituciones y la gestión.

Por lo tanto, se puede decir que la gestión implica una serie de trámites que se realizan para resolver o concluir un proyecto. La gestión debe ser integral, coherente en cuanto el desarrollo de los objetivos institucionales y las prioridades de las mismas; así como velar por el futuro que beneficien el desarrollo adecuado de la población estudiantil de los centros educativos. Esto puede dar un giro positivista, si se enseña al estudiantado el interés de ser 
partícipes e intermediarios para velar que estas conductas conflictivas no se desarrollen dentro del centro educativo. Sin perder de vista que el responsable del proceso o funcionamiento adecuado es el director o directora de la institución.

La gestión de la educación se fundamenta en el principio administrativo de hacer las cosas a través de las personas, por lo que Venegas (1993) define gestión directiva como "el proceso de conseguir ayuda y colaboración de todos los miembros del centro educativo; según sus habilidades e intereses variados para la consecución de un trabajo común en donde cada aporte personal es una parte del conjunto" (p.23). Desde esta perspectiva, la gestión tiene como principio el de trabajar con las personas para lograr las metas comunes que benefician en generar compromisos en las habilidades y según intereses propios de la organización.

\section{Conflictos estudiantiles}

En aras de conceptualizar los conflictos estudiantiles, es importante conocer lo que se entiende por conflictos y poder representar la base conceptual de la definición de lo que son conflictos estudiantiles. De esta forma, es relevante definir el término conflicto y algunas alternativas para dar respuesta positiva a diversas situaciones. Con respecto, al conflicto, Etxeberría, Esteve y Jordan (2001), diferencian conflicto de violencia, puesto que se tiende a confundir o mal interpretar los términos, de manera que no se confundan.

El conflicto se relaciona con los enfrentamientos o desacuerdos que se dan entre las personas, y que se pueden manifestar por una sencilla discusión o por la violencia, es decir la violencia es una forma de enfrentar los conflictos. Desde siempre han existido conflictos entre las personas, dentro de las causas de más fuerza es el los temas de racismo, de clases sociales, poder, egoísmos, entre otros. Provocando manifestaciones de desentendimiento, incomprensión, polémica, que han generado descontento y enojo, terminando en situaciones conflictivas, dando cabida a la violencia, que la misma es un gran problema mundial, insertada en la sociedad y por ende en el sector educativo.

El conflicto, por tanto, se refiere a la existencia de diferentes perspectivas de la realidad sin que exista precisamente el manejo de las diferencias, el conflicto tiene sus manifestaciones en diferentes espacios sociales. Ante lo anterior, Cascón (2006) concientiza a la población estudiantil sobre las acciones que se realizan, partiendo del hecho que todo acto tiene una consecuencia, ya sea negativa o positiva, y que cada persona es la única responsable de sus actos según la decisión que tome. Con base en lo anterior, los conflictos estudiantiles, serán de provecho, siempre y cuando se le dé la adecuada intervención, ya que de los errores se aprende, y para lograr esto se debe dar el debido proceso; es decir, la clave está en cómo 
tratar el conflicto, para no caer en extremos y no se produzca violencia; que se opte por una cultura de paz.

El conflicto, como parte natural de la vida cotidiana de las personas nos entrega una oportunidad para enseñar habilidades socioafectivas, importantes para vivir en forma pacífica y democrática. En ese sentido, es necesario reflexionar sobre cómo enseñar a resolver conflictos, de modo de involucrar de mejor modo estos aprendizajes.

Las organizaciones sufren de conflictos pero algunos pueden ser positivos si se aprovechan adecuadamente; y otros negativos si no se tratan adecuadamente, los cuales hay que buscar canalizarlos para enfocarlos en positivos. Junto a estos aspectos de personalidad y de desarrollo de destrezas para la conducción del centro educativo, se presenta una habilidad que se debe tomar en cuenta para responder a los múltiples retos que involucran la administración efectiva de las organizaciones educativas, donde la presencia de los conflictos no es ajena a la dinámica escolar, ya que estos son parte de la vida de las personas, tanto a nivel interpersonal como social. Así lo describen García et al. (2002), al mencionar que el conflicto en la escuela no debe evitarse ni ignorarse, sino enfrentarse para su adecuada resolución. Esta labor de resolución de los conflictos en el contexto educativo requiere también de ciertas habilidades, presentes en el perfil del profesional en administración de la educación.

Una de las estrategias en la administración de la educación que se puede implementar para el abordaje efectivo de las situaciones conflictivas dentro de las organizaciones educativas, puede estar relacionada con la toma de decisiones; aplicando un diagnóstico de la situación y posteriormente, una toma de conciencia acerca de la situación problemática existente y de los elementos involucrados.

\section{Tipos de conflictos estudiantiles}

Los conflictos estudiantiles pueden tener diversos orígenes, pero es responsabilidad del administrador de la educación conocer las distintas causas para poder actuar, de la mejor manera, en el momento de buscar o negociar las posibles soluciones, de manera que estos no interfieran con el cumplimiento de los fines y objetivos de la educación costarricense.

El conflicto no es sinónimo de violencia sino que la violencia es una de las formas que se manifiestan cuando el conflicto no es abordado adecuadamente, desde esta perspectiva deben visualizarse no como un hecho aislado e individual, sino más bien como un proceso, que tiene sus orígenes en la insatisfacción de diversas necesidades de índole económico, 
religiosas, sociales entre otros. Los cuales suelen provocar diferentes tipos de problemas, y la no resolución de estos, es lo que comúnmente provoca los conflictos, a estos se les añaden otros elementos tales como: temor, desconfianza, otros.

Las actitudes y acciones de la administración de los centros educativos determinan en gran parte el éxito del proceso que realice para la resolución del conflicto. Es importante realizar acciones preventivas y de capacitación para no limitar el trabajo al momento en que se presenta el conflicto, dado que los resultados no son igualmente satisfactorios, y para ello se requiere de un trabajo conjunto donde intervenga la comunidad educativa (Chacón et al., 2009).

El identificar las causas de los conflictos dentro de las organizaciones educativas, se debe de considerar todas las situaciones en donde él o la estudiante se encuentren involucrados y que pueden ser encargados de algún detonante de riesgo dentro de la institución. Así mismo, dentro del contexto se deben considerar la estructura social del estudiante como lo indica Fernández (2008) el cual, menciona que la escuela recibe todo tipo de individuos junto con conductas distintas. Es decir, que por la estructura social que impera hay poca satisfacción de las necesidades básicas mínimas, lo que se transforma en climas de conflictos entre los individuos. Con lo anterior, son varias las causas de los conflictos estudiantiles sobre las cuales se relacionan elementos asociados a las relaciones interpersonales, valores, intereses, discrepancias, entre otros. Por lo anterior, el profesional que ejerce la gestión de la educación, asume con responsabilidad y compromiso su tarea, en busca de una solución creativa.

\section{Referente metodológico}

El presente trabajo es una investigación descriptiva, que utiliza técnicas de investigación cualitativa y cuantitativa. Es un estudio que indaga sobre la gestión de los conflictos por parte del profesional en administración de la educación de la Escuela Barrio Limoncito, del Circuito Escolar 02 de la Dirección Regional de Limón

La población del estudio la conforman dos profesionales en administración de la educación que desempeñan el rol directivo en los centros educativos participantes; además de su personal docente, 31 en la Escuela Barrio Limoncito y 22 de la Escuela La Colina. Así mismo, la población estudiantil correspondiente a los presidentes de secciones de sexto y quinto grado de las dos escuelas en estudio, para un total de 23 estudiantes participantes, los cuales fueron seleccionados por el grado de madurez que los y las niñas reflejaran al presente trabajo, así como fueron elegidos por sus compañeros y compañeras al ser elegidos como sus representantes. 
Para recolectar la información, se aplicó una entrevista a las personas que ejercen la dirección, un cuestionario al personal docente y otro a la población estudiantil participante.

\section{Análisis de la Información}

Para una mejor interpretación de los resultados se presenta una caracterización general de la población participante en el estudio.

\section{Caracterización de la población}

Las personas que ejercen la dirección de los centros educativos que participaron en el estudio, tienen amplia experiencia laboral en el sistema educativo costarricense, con una trayectoria superior a los veinte años y en dirección de centros educativos, cuentan con una experiencia de aproximadamente más de diez años; poseen el grado de magister en el campo de la administración de la educación y se acreditan el grupo profesional PT6.

Con respecto al personal docente, en su mayoría poseen el grado académico de Licenciatura, seguido del grado académico de maestría y una minoría reportan el nivel académico de diplomado. Este personal académico, en su mayoría, son acreedores del grado profesional PT6 y la minoría tiene el grado profesional de PT5. La gran mayoría de esta población tiene estabilidad laboral ocupando su cargo en propiedad y una experiencia laboral mayor a los diez años dentro del sistema educativo costarricense.

La población estudiantil participante en la investigación posee entre diez y once años y ocupan cargos directivos dentro de sus secciones, pues se desempeñan como presidentes de sección; este puesto es elegido en forma democrática según las normas institucionales al respecto.

La información se presenta mediante cuatro componentes que corresponden a las categorías de análisis propuestas en los objetivos de la investigación. Se ofrece un marco explicativo a los hallazgos del estudio desde la administración de la educación, se rescatan aportes que fundamentan la propuesta de intervención que desde la gestión de la educación es posible aplicarla en los centros educativos, para un adecuado abordaje de los conflictos estudiantiles.

Seguidamente, se ilustra en la siguiente tabla, las respectivas categorías de análisis que orientan esta investigación, junto con los indicadores que permitieron los principales hallazgos del estudio. 
URL: http://revistas.ucr.ac.cr/index.php/gestedu

Tabla 1

Categorías de análisis e indicadores sobre el análisis desde la gestión de los conflictos estudiantiles

Categorías de análisis

Conflictos estudiantile
Indicadores

\begin{tabular}{|c|c|}
\hline Conflictos estudiantile & 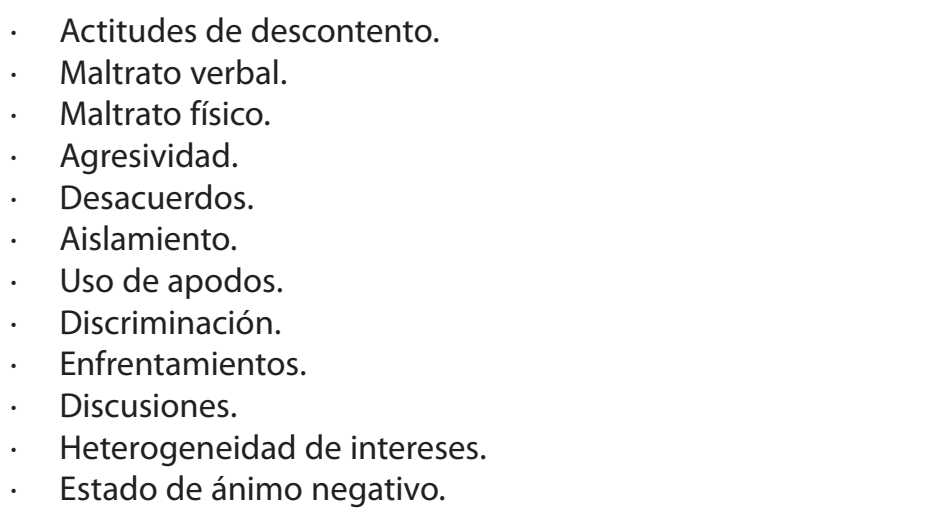 \\
\hline $\begin{array}{l}\text { Causas que generan los conflictos } \\
\text { estudiantiles }\end{array}$ & 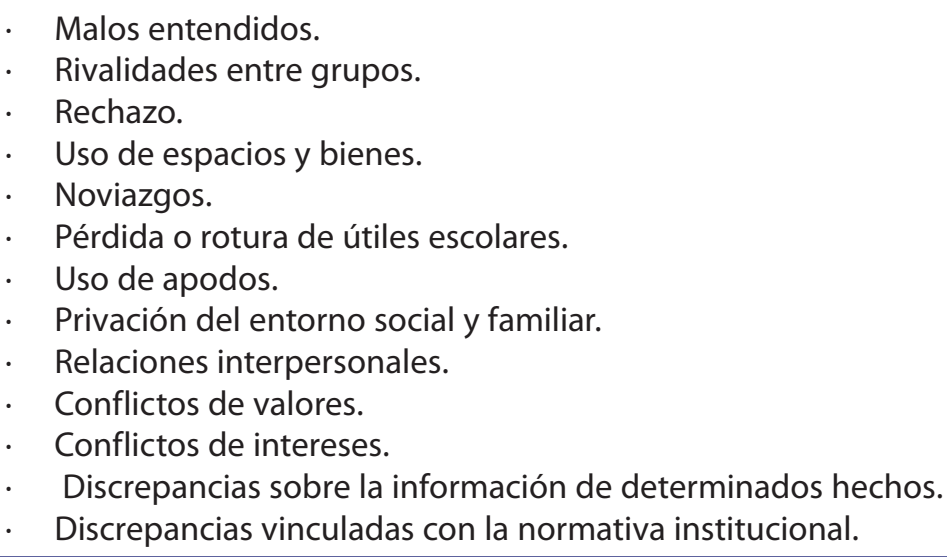 \\
\hline Estrategias de gestión & $\begin{array}{l}\text { Trato humanitario. } \\
\text {. } \quad \text { Justicia en el actuar } \\
\text {. } \quad \text { Participación a los miembros afectados (diálogo). } \\
\text {. } \\
\text { Acciones que fomenten ambientes de aprendizaje de calidad } \\
\text { mediante una adecuada convivencia estudiantil. }\end{array}$ \\
\hline $\begin{array}{l}\text { Obstáculos que los conflictos } \\
\text { estudiantiles, le generan a la gestión de } \\
\text { los centros educativos }\end{array}$ & $\begin{array}{l}\text { - Sano desarrollo y progreso social de las instituciones. } \\
\text { - Se afecta el cumplimiento de los objetivos institucionales. } \\
\text {. }\end{array}$ \\
\hline
\end{tabular}

Fuente: López, 2012. Operacionalización metodológica del estudio sobre el abordaje desde la gestión de los conflictos estudiantiles, Escuelas Barrio Limoncito y La Colina, Circuito 02, Dirección Regional de Educación de Limón. 
Para la Escuela Barrio Limoncito, la investigación determinó que el maltrato verbal (50\%), maltrato físico (50\%), las discusiones (53,3\%), los estados de ánimo negativos (50\%) y la discriminación (46,6\%), son los principales conflictos estudiantiles que la institución enfrenta, a criterio del $50 \%$ de los docentes. La dirección por su parte, coincide en esta priorización externada por el personal docente. Por su lado, la mayoría de los estudiantes participantes consideran como principales conflictos estudiantiles el uso de apodos, seguido de las discusiones.

Con respecto a estos hallazgos, es importante considerar que los conflictos estudiantiles son un desafío que la gestión de los centros educativos enfrenta y en especial, en zonas urbano marginal como es el contexto donde se ubica esta institución. La gestión de la educación asume relevancia en este temática, en el sentido de que le corresponde, dentro del sistema educativo, velar por el desarrollo y cumplimiento adecuado de los propósitos institucionales, de manera que un adecuado abordaje de los conflictos estudiantiles es una herramienta fundamental en el ejercicio de la administración de la educación, para que al centro educativo no se le obstaculice el alcance de los objetivos institucionales según las políticas educativas (Garbanzo y Orozco, 2010).

Estos resultados presentan gran similitud con la Escuela La Colina, la cual también, pertenece al mismo contexto. La información recopilada evidencia que las discusiones (73,6\%), el maltrato verbal (63\%), uso de apodos (63\%), las discusiones $(52,6 \%)$, son los principales conflictos estudiantiles que la institución enfrenta a criterio de la dirección y de la mayoría del personal docente participante. Para la mayoría de los estudiantes, es el uso de apodos, seguido de las discusiones, los principales conflictos estudiantiles que enfrentan.

Se evidencia en ambas instituciones una importante coincidencia en que los principales conflictos estudiantiles están asociados a las discusiones, uso de apodos, maltrato físico y verbal, además de los estados de ánimo negativos. Estos hallazgos coinciden con el hecho de que, por lo general, este tipo de conflictos se relacionan con enfrentamientos, ofensas, insultos y el uso de palabras soeces, por lo que es importante de considerar dentro de las estrategias de gestión que implementan los profesionales en administración de la educación que ejercen la dirección en los centros educativos, en el sentido de que se deben atender en forma oportuna y minimizar los efectos de estas situaciones al carecer de una adecuado abordaje desde la gestión, partiendo de que, como lo expone Garbanzo y Orozco (2010), le corresponde liderar los procesos estratégicos necesarios para el buen funcionamiento institucional y alcanzar los objetivos propuestos, según las políticas educativas regionales y nacionales.

Con el propósito de abordar estas manifestaciones que pueden afectar en forma negativa los centros educativos; las organizaciones educativas requieren de parte de 
la gestión, un adecuado abordaje de los conflictos estudiantiles con el propósito de que no afecten el desarrollo del proceso educativo que se imparte en la institución y pueda cumplirse lo establecido en los fines y objetivos de la educación costarricense. Es importante tener en cuenta que los conflictos estudiantiles son parte de la cotidianidad, del quehacer organizacional en los centros educativos; criterios en los cuales coinciden Etxeberría et al. (2001) al considerar que responden a situaciones cotidianas que se enfrenta en las escuelas, donde es usual encontrar enfrentamientos de intereses, discusiones y la importancia de proporcionar un adecuado abordaje. Así las cosas dentro de las organizaciones educativas, lejos de pensar en la eliminación de ellos, se deben trabajar con procesos de gestión pertinentes que promuevan la prevención y el abordaje correcto de los mismos.

Los conflictos estudiantiles son una serie de manifestaciones de acuerdo al contexto, que se pueden presentar con actitudes de descontento, desacuerdos, maltrato físico y verbal, que a su vez se asocia con agresiones, aislamiento, discriminación (Chacón et al., 2009). Estas manifestaciones vienen a ser parte de la dinámica escolar, son situaciones características de la convivencia humana como seres sociales que interactúan, donde la administración de la educación asume una función estratégica, al ser consciente de esta realidad organizacional en la dinámica estudiantil, dándose en algunas instituciones con mayor incidencia. Al respecto, se espera de la gestión respuestas competentes en busca del cumplimiento de los objetivos institucionales.

En general, el estudio pudo determinar que el maltrato verbal, maltrato físico, las discusiones, la discriminación, las discusiones y el uso de apodos entre ambas instituciones son los principales conflictos estudiantiles que presenta.

Los gestores y gestoras de la educación deben poseer una serie de características y habilidades que les permitan tener la experiencia de contribuir al cumplimiento de sus responsabilidades dentro del centro educativo que dirige, de una forma eficiente. Parte de sus funciones es procurar un ambiente armonioso, donde todo tipo de conflicto estudiantil, reciba un abordaje objetivo y maduro.

Al respecto, Chiavenato (2006), considera como principales funciones de la gestión los procesos de planificación, organización, dirección y control en el uso de recursos para lograr los objetivos institucionales. Este planteamiento lo refuerzan Garbanzo y Orozco (2010), al indicar que una educación en la que los valores como dignidad humana, justicia social, igualdad de derechos, oportunidades, libertad, participación y transparencia, entre otros, constituyen la base sobre la que se generen auténticos procesos educativos de calidad. Para la indagación de las estrategias de gestión ante los conflictos estudiantiles se trabaja a partir de los siguientes indicadores: 
- Trato humanitario

- Justicia en el actuar

- Igualdad de derechos y oportunidades a las partes afectadas

- Participación a los miembros afectados (diálogo)

- Transparencia en el proceso

- Acciones que fomenten ambientes de aprendizaje de calidad mediante una adecuada convivencia estudiantil

Según la información obtenida por el personal docente, las acciones que se ejercen desde la gestión de la educación en la Escuela Barrio Limoncito, promueve dentro de la institución, el trato humanitario $(76,6 \%)$, la transparencia en el proceso $(76,6 \%)$, la aplicación de acciones que fomenten ambientes de aprendizaje de calidad mediante una adecuada convivencia estudiantil $(76,6 \%)$, justicia al actuar $(73,3 \%)$, participación de los miembros afectados por medio del dialogo $(73,3 \%)$ e igualdad de derechos y oportunidades de las partes $(73,3 \%)$. Todos estos componentes son imprescindibles de considerar por parte de la administración de las organizaciones educativas, los cuales son claramente visibilizados en la Escuela Limoncito. En este centro educativo, estos valores alcanzan porcentajes que superan el $73,3 \%$. Ante las diferentes estrategias de la gestión en la organización educativa, Kinicki y Kreitner (2003) indican que los conflictos estudiantiles pueden ser funcionales o constructivos, ya que favorecen el funcionamiento de la organización educativa, confirmando la percepción suministrada por el personal docente.

Por su parte, la población estudiantil participante, considera que las acciones por parte del profesional en administración de la educación se clasifican de la siguiente manera: participación de los miembros afectados por medio del diálogo (53,3\%), transparencia en el proceso $(46,6 \%)$, justicia al actuar (40\%) e igualdad de derechos y oportunidades de las partes (33,3\%); estos datos muestran una valoración inferior a la proporcionada por el personal docente, dado que los estudiantes no consideran que la gestión del centro educativo en general, lidere procesos de gestión caracterizados por justicia, igualdad de derechos y oportunidades y transparencia; elementos a considerar desde la dirección de los centros educativos. o contar con una política de gestión en este sentido, es difícil para alcanzar un adecuado desarrollo de los mismos y por ende, del proceso enseñanza-aprendizaje que se imparte. Según Kinicki y Kreitner (2003), esta percepción de la población estudiantil, pone en evidencia la otra categoría que muestra 
el autor sobre los conflictos estudiantiles, los cuales se consideran como disfuncionales al dificultar el rendimiento de la organización y evidenciar los diversos riesgos entre las partes.

Por su parte, la dirección del centro educativo indica que las estrategias aplicadas en casos de conflictos estudiantiles se orientan a realizar el debido proceso con transparencia, justicia en el actuar, brindando la participación de los mismos respetando sus derechos y con un trato humanitario y adecuado, opinión que contrasta con la externada por los y las estudiantes, aunque si coincide, en gran medida, con el personal docente participante. Esta situación llama a la reflexión en la necesidad de una mayor articulación con las necesidades estudiantiles y las consideradas por la dirección y personal docente en lo que a conflictos estudiantiles se refiere; pareciera que hay una gran distancia entre lo que esperan estudiantes y personal directivo y docente, en la institución. No se debe olvidar, que las estrategias de gestión son la capacidad de conducción de los y las profesionales en administración de la educación (Braslavsky 2006, citado por Garbanzo y Orozco, 2010), mientras se hace referencia a la importancia del rol directivo como potencial gestor en las organizaciones educativas para promover aprendizajes de calidad. De esta manera, para que las estrategias sean efectivas, es importante llegarle a la población, en este caso estudiantil, en forma acertada a sus necesidades.

Estos resultados presentan semejanza con la Escuela La Colina, la cual también, pertenece al mismo contexto. La información adquirida por los diferentes sujetos participantes indican que el personal docente considera que las acciones de gestión que más aplica la profesional en administración de la educación de la institución, es la igualdad de derechos y oportunidades a las partes afectadas $(94,7 \%)$, la participación a los miembros afectados $(94,7 \%)$, el trato humanitario $(84,2 \%)$, la justicia al actuar $(78,9 \%)$ y la transparencia en el proceso $(78,9 \%)$.

Por su parte, la población estudiantil considera que la dirección aplica como acción prioritaria la participación de los miembros afectados (50\%), igualdad de derechos y oportunidades a las partes afectadas (37,5\%) y acciones que fomentan ambientes de aprendizaje de calidad mediante una adecuada convivencia estudiantil $(37,5 \%)$. En este centro educativo, se presenta algo similar a la escuela Barrio Limoncito, puesto que el personal docente considera que las acciones de parte de la administración son adecuadas y mantiene un porcentaje del $78,9 \%$ hacia arriba; mientras que la población estudiantil no está de acuerdo con las acciones abordadas por parte de la administración, y esto lo confirman los bajos porcentajes que reflejan la opinión de la población estudiantil sobre dichas acciones. 
La dirección de la institución indica que el trato humanitario junto con la justicia en el actuar, así como, la participación e igualdad de justicia de las partes involucradas, son las acciones que aplica con más frecuencia ante este tipo de situaciones. Llama la atención, que existan distanciamientos tan grandes en la percepción de la población estudiantil ante las acciones de gestión que aplican los profesionales en administración de la educación, en relación con lo que percibe el personal docente y la dirección de la organización; por consiguiente, se busca minimizar estos distanciamientos por medio de la aplicación de estrategias al respecto.

Distintas estrategias como grupos focales, talleres y otros representan opciones donde se les permite a los y las estudiantes externar sus puntos de vista, en busca de alcanzar el equilibrio adecuado entres las partes organizacionales. De esta manera, los conflictos estudiantiles pueden generarse como consecuencia de emociones negativas, a escasa o falsa comunicación, así como también, pueden surgir solamente cuando algunas personas intentan interponer por la fuerza, un conjunto de valores o pretenden que tengan vigencia exclusiva en un sistema de valores que no admite creencias divergentes y aceptando que lo que realizan es suficiente, sin dar la importancia a las opiniones de las partes.

La gestión en las organizaciones educativas se fundamenta en el principio administrativo de hacer las cosas a través de la persona; al respecto, Chiavenato (2000) afirma que la eficacia con que se organice el trabajo entre las personas en la organización, de manera conjunta para conseguir objetivos comunes, depende de la capacidad de quienes ejercen la función administrativa. Desde la visión de la administración, la gestión de la educación tiene como principal objetivo trabajar con las personas para lograr metas comunes que beneficien y ayuden a lograr el mejoramiento y la calidad de la educación; situación que pareciera no estarse dando entre la dirección, el personal docente y la población estudiantil, con respecto a las estrategias empleadas en la solución de conflictos estudiantiles, en donde el rol directivo en una escuela con necesidad de cambio, en el manejo de los conflictos, necesita una transformación educativa, pensando este proceso como una necesidad de reflexión, análisis y cuestionamiento de sus propuestas, que orientan y reorientan la marcha institucional, con objetivo de ajustarse a las necesidades de las demandas del alumnado, sin perder de vista los fines de la educación en formar ciudadanos amantes y respetuosos a la patria.

Por ende, se consideran como acciones de la gestión que deben contemplar los profesionales en administración de la educación en los centros educativos, en cuanto a los conflictos estudiantiles, las siguientes: 


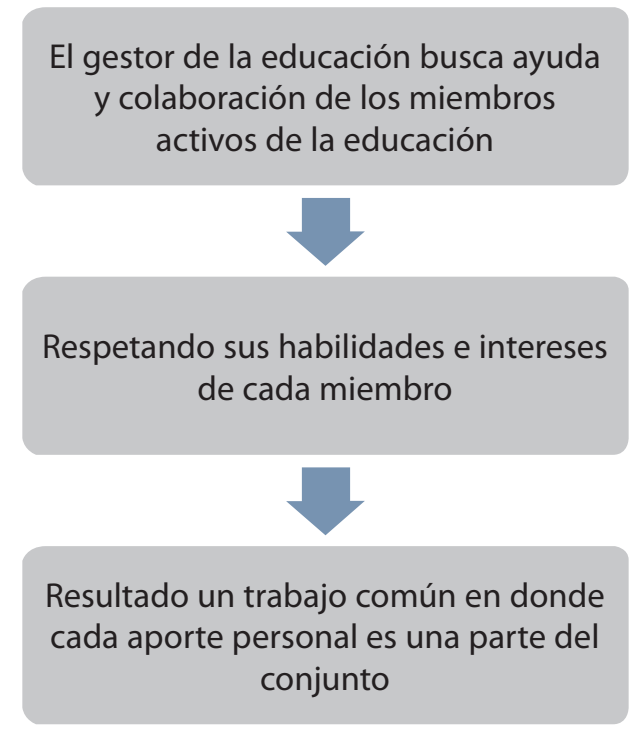

Figura 1. Acciones a considerar por la gestión de las organizaciones educativas en el abordaje de los conflictos estudiantiles

Fuente: López, 2012.

Lo anterior, implica cambios tales que se modifiquen radicalmente las configuraciones institucionales. Algunos de los ambientes procedentes de los conflictos estudiantiles que obstaculizan el buen desarrollo y progreso social de las instituciones en estudio, atentando con el cumplimiento de los objetivos institucionales y en consecuencia, los procesos educativos se ven limitados en cuanto a su calidad, en algunos casos se da producto del inadecuado abordaje. Por consiguiente, en muchas ocasiones las consecuencias negativas de un conflicto estudiantil no es necesariamente por la gravedad de la situación, sino por un abordaje inadecuado de los mismos. Al respecto, Banz (2008) se refiere a que es "muy frecuentemente, las consecuencias negativas del conflicto no provienen del conflicto en sí mismo, sino de la manera como el conflicto es percibido y manejado por las partes" (p.1). En realidad un conflicto estudiantil determinado, no es de mayor trascendencia, si se cuenta con un adecuado abordaje de parte de la gestión de las organizaciones educativas, mientras en otras ocasiones, algo más sencillo se convierte en algo difícil de controlar, por la falta de atención adecuada.

Las actividades sugeridas que podrían obstaculizar los conflictos estudiantiles en la gestión de los centros educativos, se enfocan hacia un sano desempeño y progreso social que afecta el cumplimiento de los objetivos y a la vez, los procesos educativos enfrentan limitaciones, estos desde la perspectiva del personal docente y las profesionales en administración de la 
educación de las escuela Barrio Limoncito y La Colina. La búsqueda de disminuir los obstáculos que generan los conflictos estudiantiles, inician con la caracterización desde la relación docente-dirección, reconociendo una dinámica relacional de la comunidad educativa; así como la implementación de un plan de formación para la administración y la gestión del conflicto dentro del contexto escolar. La población estudiantil debe aprender a socializar, negociar y entender hasta donde llegan sus límites, se les debe enseñar a vivir en sociedad. Los gestores y gestoras de la educación en los centros educativos, deben proponer la formación de personas capaces de aceptar a otros y, de esta manera, enfrentar los diversos obstáculos que enfrentan los conflictos estudiantiles.

La comunidad educativa de los centros educativos en estudio, está consciente que tanto a lo interno como a lo externo de la institución, existen situaciones relacionadas con los conflictos estudiantiles. Estos se manifiestan de formas diversas: conflictos entre estudiantes, con estudiantes, entre estudiantes y docentes, entre otros. Existe una preocupación real en relación con las manifestaciones de los conflictos, sobre todo por la impotencia que sienten ante algunos acontecimientos relacionados con este fenómeno. Es evidente que la gestión administrativa de las escuela Barrio Limoncito y La Colina, presenta importantes carencias para atender preventivamente los conflictos estudiantiles desde las funciones de planificación, organización y seguimiento; a pesar de que han sido identificadas las principales manifestaciones de conflictos estudiantiles, no se logra un abordaje adecuado por parte de la administración de la educación en la creación y aplicación de estrategias para éstas y otras necesidades detectadas en el diagnóstico institucional, principalmente la desarticulación es percibida por la población estudiantil.

En general, la investigación muestra vacios en la forma en que se gestionan los conflictos estudiantiles. El personal docente reconoce que, a nivel institucional, se abordan, pero son insuficientes. Lo que evidencia la no existencia de un programa institucional para la prevención e intervención de los conflictos estudiantiles, exponiendo que la gestión de la educación no logra cumplir con su rol de forma apropiada, como lo menciona Braslavsky (2006), citado por Garbanzo y Orozco (2010), el cual resalta la importancia de la capacidad de conducción de las direcciones en las instituciones, de manera que adquiera relevancia el rol directivo como potencial gestor en las organizaciones educativas para promover aprendizajes de calidad.

Una de las estrategias que se aplica en el campo administrativo, en relación con los conflictos estudiantiles, es la mediación; para esto, es imprescindible la utilización del diálogo y el consenso entre las partes. La población estudiantil reconoce que, a nivel interno se realizan acciones para combatir los conflictos estudiantes; asimismo, las consideraron insuficientes. Además, consideran que ante estos acontecimientos, tanto la dirección como el personal docente, se han mostrado indiferentes. 
De esta forma, se determina que si se han dado esfuerzos en las organizaciones para la intervención de los conflictos estudiantiles. Sin embargo, estos esfuerzos son aislados, ya que algunos docentes no aplican el reglamento y dejan pasar situaciones y evitar problemas.

La no existencia de un plan y de un comité que colabore con esto dificulta la labor. La población estudiantil y el personal docente demandaron mayor presencia de la dirección en los pasillos, las aulas, entre otros, más en uno de los centros educativos participantes en el estudio.

Debería hacerse más evidente, las acciones que a nivel preventivo e informativo se realizan a lo interno y externo de la institución educativa.

Las instituciones educativas cuentan con un equipo Interdisciplinario (profesionales en orientación, trabajo social y psicología) para la gestión e intervención de las diferentes problemáticas que se presentan en el nivel interno y externo. Cada uno, de acuerdo con el análisis de los datos, realiza diferentes acciones para el abordaje de los conflictos. Sin embargo, no poseen un programa sistematizado de intervención y prevención de los conflictos. De esta manera, no se demostró que exista un adecuado abordaje institucional desde la gestión con resultados pertinentes, para atender este tipo de situaciones. Por esto, es prioritario que se construya, desde la gestión de estos centros educativos, estrategias que guíen un adecuado abordaje de los conflictos estudiantiles.

La dirección debe informar a toda la comunidad educativa, sobre los diferentes procesos, proyectos y programas que, en el nivel institucional se implementan en torno al abordaje de los conflictos estudiantiles, con el fin de involucrar la comunidad educativa; esto incluye el reglamento interno. De esta forma, se asegura que la información llegue a sus destinatarios y se hagan esfuerzos por su adecuada aplicación y lograr un ambiente armonioso para que el proceso de la enseñanza y aprendizaje se lleve a cabo en mejores condiciones.

Al estar los conflictos estudiantiles relacionados con situaciones cotidianas de la vida social y escolar, tal y como lo expresan Antúnez, Boqué, Casamayor, Cela, Díez de Ulzurrúm, Fajardo, Funes, Garrell, Mainer, Martí, Massager, Moneo, Notó, Perales, Rigoll y Tudela (2000), deben, con mayor razón, abordarse con estrategias prioritarias en la gestión de las organizaciones educativas. Sin embargo, un conflicto que no es abordado desde sus inicios, en forma preventiva, puede desatar la violencia, pues así, es percibido por los sujetos participantes en esta investigación, al mencionar que al no haber abordaje directo con las personas que tienen conflictos se desencadenan agresiones físicas más o menos violentas. 
Al respecto, Chiavenato (2006) señala que la administración debe integrar los recursos humanos y materiales y dirigirlos en función del alcance de los objetivos organizacionales. El profesional en administración de la educación debe tomar conciencia de la problemática presente en su organización, así como de los sujetos involucrados en el conflicto y actuar de forma estratégica, como lo afirman García et al. (2002) al expresar que una de las estrategias en la administración de la educación que se puede implementar para el abordaje efectivo de las situaciones conflictivas dentro de las organizaciones educativas, puede estar relacionada con la toma de decisiones.

Es por lo anterior, que interesa en este estudio elaborar una propuesta que fortalezca el abordaje de los conflictos estudiantiles en la gestión de la educación desde las principales debilidades encontradas, como lo son la no correspondencia en las acciones realizadas por parte de los profesionales en administración de la educación para abordar los conflictos estudiantiles y el distanciamiento existente, desde la percepción del personal docente y la población estudiantil, con respecto a este abordaje.

También, representa una debilidad organizacional en esta investigación, la subutilización de parte de la administración de la educación de estos centros educativos con respecto al aprovechamiento de los profesionales con que se cuenta en la institución de los equipos interdisciplinarios conformado por profesionales en orientación, trabajo social y psicología; equipos que deben representar un importante apoyo a la gestión de estas organizaciones educativas en la intervención de las diferentes problemáticas que se presentan a lo interno y externo, en lo que al abordaje de los conflictos estudiantiles se refiere.

\section{Conclusiones}

Los diferentes conflictos estudiantiles detectados en los centros educativos de la investigación son: actitudes de descontento, desacuerdos, maltrato verbal y/o físico, expresiones de agresividad o violencia, cambios de actitudes, aislamiento y discriminación, manifestaciones que inciden de una u otra forma en la gestión de los centros educativos.

Los principales causantes de los conflictos estudiantiles dentro de la institución se asocian con el maltrato verbal, discusiones entre estudiantes, así como el uso de apodos entre ellos mismos.

Los profesionales en la gestión de la educación deben brindar un adecuado abordaje de los conflictos estudiantiles, a través de la generación de estrategias colaborativas, con la finalidad de que no se entorpezca el proceso de formación del estudiantado, de manera que 
lleguen a ser ciudadanos conocedores de sus obligaciones y responsabilidades con la sociedad, favoreciendo un proyecto social más inclusivo y competitivo.

Estas estrategias colaborativas deben involucrar a los diferentes actores de la comunidad educativa, por lo que le corresponde a los profesionales en administración de la educación que gestionan el accionar en los centros educativos, ofrecer estos espacios que consoliden una visión integral de la resolución de estos temas

A pesar de que han sido identificadas en las organizaciones participantes del estudio, las principales manifestaciones de conflictos estudiantiles, es necesario que la administración de la educación en estas instituciones, incorporen estrategias dentro del plan institucional donde se involucren a los profesionales de orientación, trabajo social y psicología que conforman el equipo interdisciplinario, para una adecuado abordaje estos conflictos estudiantiles, de manera que no se vea limitado el desarrollo institucional.

Queda claro el compromiso e importancia por parte del personal docente y de la administración de la educación en cuanto a la prevención, intervención y resolución del conflicto en forma pacífica, reflejando la atención hacia las necesidades del estudiantado, que es hacia donde deben dirigirse los esfuerzos de formación, y alcanzar satisfactoriamente los fines de la educación costarricense.

Se necesita que en la gestión de la educación se generen espacios para que la comunidad educativa en conjunto, forme estrategias para implementar el desarrollo de espacios armonioso dentro de la institución educativa, para resolver las situaciones conflictivas de forma eficiente.

La administración de la institución tiene disponibilidad para atender los diversos conflictos estudiantiles, en busca de tomar adecuadas decisiones y poner en marcha las acciones que beneficien al centro educativo; acciones que desde la gestión deben seguir cumpliendo.

Los profesionales en administración de la educación deben conocer las características propias del contexto geográfico, cultural y social, pues estas determinan la forma de ser del estudiantado y utilizar estas herramientas en beneficio para lograr los objetivos de la educación de la calidad de la enseñanza.

Así, en la gestión de la educación debe continuar realizando esfuerzos para alcanzar una transformación cultural para abordar de manera pacífica cualquier conflicto estudiantil que se presente dentro de la institución, sin perder de vista el papel fundamental que tiene la educación de formar ciudadanos responsables y amantes de su patria.

Tanto las profesionales en administración de la educación como el personal docente están en la mejor disponibilidad de desarrollar estrategias de apoyo que minimicen los principales 
obstáculos que se presentan en los centros educativos; condiciones institucionales a tomar en cuenta dentro del plan institucional y poner en práctica políticas en este sentido.

Es necesario que la administración de la educación aplique acciones eficientes para abordar los conflictos estudiantiles; proporcionando al personal docente herramientas para resolver los principales obstáculos que los conflictos estudiantiles generan a las organizaciones educativas que pueden afectar el desempeño institucional.

Según lo indagado por los sujetos de la investigación existen diversos obstáculos que se enfrentan ante el abordaje adecuado de los conflictos estudiantiles, se resaltan entre los principales el que se ve afectado el cumplimiento de los objetivos institucionales, así como las limitaciones a las que se exponen los procesos educativos y se altera un sano desarrollo y progreso social dentro de las organizaciones.

\section{Propuesta alternativa para la gestión del abordaje de conflictos estudiantiles}

Para una adecuada gestión del abordaje de los conflictos estudiantiles de las escuelas en estudio, se desarrolla una propuesta que consiste en un taller integrado en tres sesiones, por medio de las cuales se pueden plantear estrategias para la prevención y atención de estas situaciones en los centros educativos.

La idea, es crear un espacio en el cual la población estudiantil pueda expresar, con libertad y respeto, su percepción de las necesidades en las acciones que realiza la dirección del centro educativo en la forma que se abordan los diversos conflictos estudiantiles que se presentan. Así mismo, se propone utilizar el recurso profesional con que cuenta la institución, como apoyo para la implementación del taller, con la participación del equipo interdisciplinario conformado por profesionales en orientación, trabajo social y psicología, como agentes colaboradores para la gestión e intervención de las diferentes problemáticas que se presentan en la organización educativa.

En el desarrollo del taller integrado se pretende la participación de los actores involucrados, personal docente, población estudiantil y profesionales en administración de la educación, en conjunto con el equipo interdisciplinarios como agentes facilitadores de la actividad. Para ello, se proponen diferentes etapas que permitan el adecuado abordaje de los conflictos estudiantiles en forma colaborativa, con sesiones orientadas a promover espacios de reflexión sobre las implicaciones de los conflictos estudiantiles en el desarrollo académico del estudiantado y el reconocimiento de las responsabilidades que tiene cada actor de la comunidad educativa, en el adecuado abordaje de los conflictos estudiantiles, así como la confección de un protocolo en ese sentido, a través de momentos de intervención como se ilustran en la siguiente figura: 


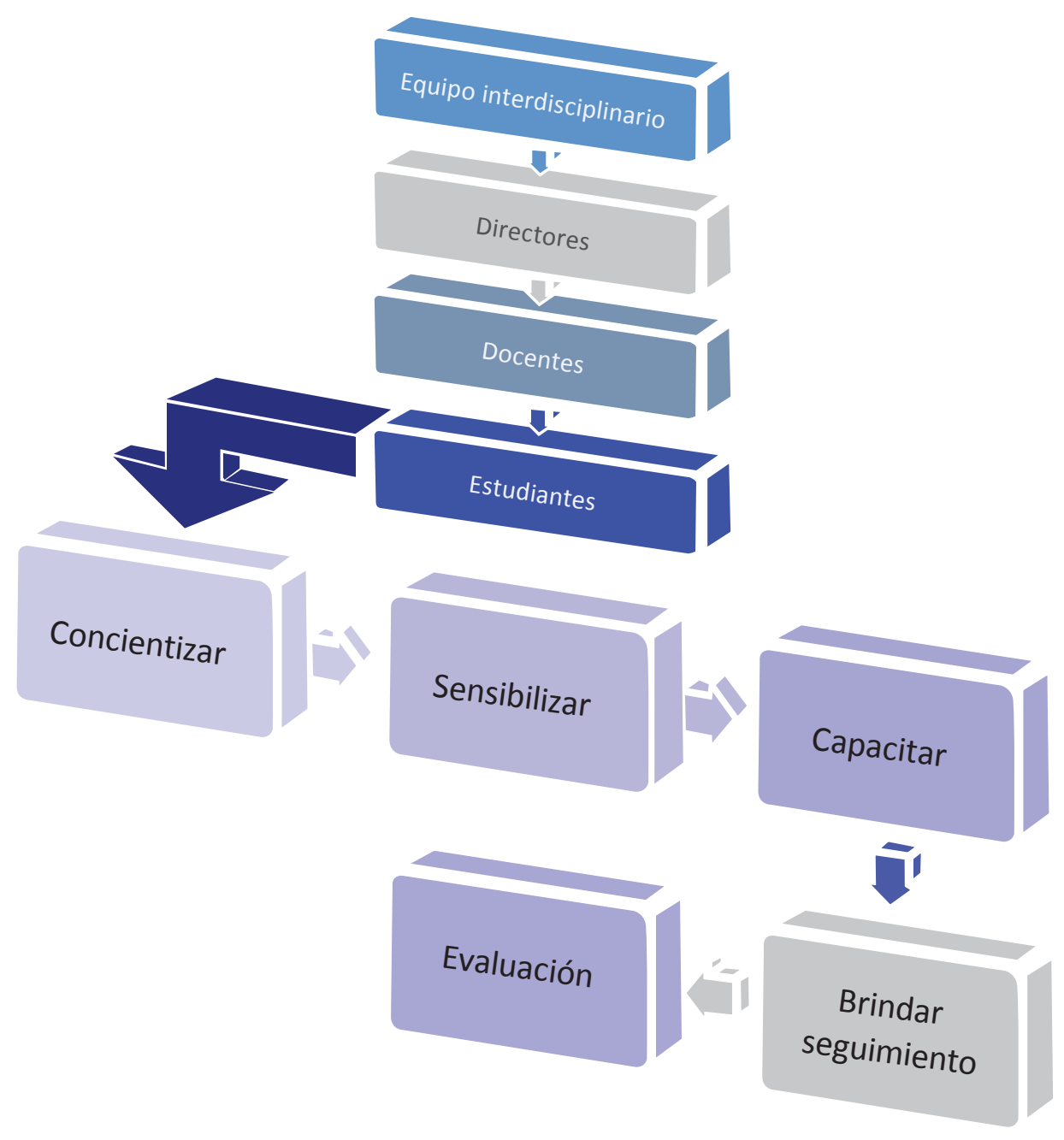

Figura 2. Población y etapas de seguimiento para la aplicación de la presente propuesta

Fuente: López, 2012. Elaboración propia.

Se espera de esta forma, poder concretar esa articulación conjunta que se espera entre los diferentes participantes de la comunidad educativa para un adecuado abordaje de los conflictos estudiantiles. 


\section{Referencias}

Antúnez, S., Boqué, M. C., Casamayor, G., Cela, J., Diez de Ulzurrúm, A., Fajardo, P., Funes, J.,Garrell, T. ... Tudela, P. (2000). Disciplina y convivencia en la institución escolar. Barcelona,: Graó.

Argudín, Y. (2006). Educación basada en competencias. México: Trillas.

Banz, C. (2008). Aprender a resolver conflictos de forma colaborativa y autónoma: Un objetivo educativo fundamental. Educar Chile. Recuperado de http://www.educarchile.cl/UserFiles/ P0032/File/apoyo_emocional/Docentes/6a\%20\%20\%20resolver_conflictos.pdf

Cascón, F. (febrero, 2006). Apuntes sobre educar en y para el conflicto y la convivencia. Revista Andalucía Educativa, 53, 24-27. Recuperado de http://pacoc.pangea.org/documentos/_ andalucia_educativa_paco.pdf

Castro, A. Z. (2012). Gestión de liderazgo y valores en el Instituto Técnico Luis Rogerio González de la Ciudad de Azognes, provincia del Cañar durante el período escolar 2010-2011. (Tesis de maestría). Universidad Técnica Particular de Loja. Ecuador. Recuperado de http:// dspace.utpl.edu.ec/bitstream/123456789/3144/1/Tesis\%20de\%20Castro\%20Salazar\%20 Ana\%20Zulema.pdf

Chacón, L., Elizondo, Y, Fernández, M. I., Triana, J. y Umaña, E. M. (2009). Abordaje docente y administrativo de los conflictos estudiantiles en el campo de la educación secundaria. (Tesis de licenciatura). Universidad de Costa Rica. San José. Costa Rica.

Chacón , A. (2011). Análisis de la gestión de los conflictos estudiantiles en el Liceo de Costa Rica, Circuito 02 de la Dirección Regional de San José Central. (Tesis de Maestría Profesional). Universidad de Costa Rica. San José, Costa Rica.

Chiavenato, I. (2000). Introducción a la teoría general de la administración. México: McGraw-Hill.

Chiavenato, I. (2006). Introducción a la teoría general de la administración. México: McGraw-Hill.

Consejo Nacional de Rectores (CONARE). (2009). Viaje al desarrollo humano sostenible: En la región centroamericana. Módulo educativo para segundo ciclo. Programa Estado de la Nación. San José, Costa Rica: Autor.

Delors, J., Mufti, I., Amagi, I., Carneiro, R., Chung, F., Geremek, B. y Nanzhao, Z. (1996). La educación encierra un tesoro. (Informe a la UNESCO de la Comisión Internacional sobre educación para el S.XXI [Compendio]). Francia: Santillana.

Durán, R. (2007). La administración educativa como área de trabajo pedagógico. Recuperado de www.poedagogium.com/revista/index.php 
Etxeberría, F., Esteve, J. M. y Jordan, J. A. (2001). La escuela y la crisis social. En Ortega, P. (Coord.). Conflicto, violencia y educación. Actas del Siglo XX Seminario Interuniversitario e Teoría de la Educación. Murcia: Cajamurcia.

Fernández, I. (2008). Prevención de la violencia y resolución de conflictos. España: Narcea.

Fernández, M. (2001). Gestión de instituciones educativas inteligentes. España: McGraw-Hill.

Gairín , J. y Dander, P. (2002). Organización de centros educativos. Barcelona: Praxis.

García, J. y García, A. (1996). Teoría de la educación. España: Salamanca.

García, N., Rojas, M. E. y Campos, N. (2002). La administración escolar y el mejoramiento de las instituciones educativas. Para el cambio y el mejoramiento de las instituciones educativas. San José, Costa Rica. EUCR.

Garbanzo, G. y Orozco, V. H. (2010). Liderazgo para una gestión moderna de procesos educativos. Revista Educación, 34(1), 15-29. Recuperado de http://redalyc.uaemex.mx/ redalyc/pdf/440/44013961001.pdf

Jaramillo, J. (2004). La evolución de la cultura de las cavernas a la globalización del conocimiento. San José, Costa Rica: EUCR.

Kinicki, A. y Kreitner, R. (2003). Comportamiento organizacional: Conceptos, problemas y prácticas. México: McGraw-Hill.

Koontz, H. y Weihrich, W. (1990). Administración una perspectiva global. México: McGraw-Hill.

Ministerio de Educación Pública (MEP). (1994). Política educativa hacia el siglo XXI. San José, Costa Rica: Autor.

Ministerio de Educación Pública (MEP). (2011). Programa nacional de convivencia en centros educativos. San José, Costa Rica: Autor.

Smith, L. (1996). Lecturas críticas sobre Piaget. Londres: Routledge.

Rodríguez, J. (2007). Análisis de los procedimientos utilizados para resolver el conflicto en una organización educativa privada del Cantón de Montes de Oca. (Tesis de licenciatura). San José, Costa Rica.

Romero, C. (2004). La escuela media en la sociedad del conocimiento. Ideas y herramientas para la gestión educativa. Autoevaluación y plane de mejorara. Argentina: Ediciones Novedades Educativas. 
Taberne, J. (2009). Sociología y educación. El sistema educativo en sociedades modernas. Funciones, cambios y conflictos. Madrid: Tecnos.

UNESCO. (1996). Hacia las sociedades del conocimiento. Recuperado de http://unesdoc.unesco. org/images/0014/001419/141908.pdf

Vasconez, J. L. (2012). Gestión, liderazgo y valores en la administración del Colegio Nacional Técnico Agropecuario "Salinas" perteneciente a la Parroquia Salinas, durante el año lectivo 2010-2011. (Tesis de Maestría). Universidad Técnica Particular de Loja. Ecuador. Recuperado de http://cepra.utpl.edu.ec/bitstream/123456789/3120/1/Tesis\%20de\%20 Vasconez\%20Vega\%20Jenny\%20Lorena.pdf

Venegas, P. (1993). El qué y para qué de la administración. Programa de Capacitación en Administración Educativa (PROCAE). Ministerio de Educación Pública. San José, Costa Rica: PROCAE. 